\title{
Pilot study to introduce a notification card for partner notification of sexually transmitted infections in Catalonia, Spain, June 2010 to June 2011
}

M J Tuneu ${ }^{1,2}$, X Vallès ${ }^{1}$, D Carnicer-Pont (dcarnicer@iconcologia.net)1,3,4, M J Barberá5, P Godoy 4,6, A Avecilla-Palau ${ }^{7}$, B Jordà8 ${ }^{\text {, E }}$ Lopez-Grado, D Rivero $^{10}$, A Vives ${ }^{11}$, A Acera ${ }^{12}$, R Almirall ${ }^{13}$, N Crespo ${ }^{14}$, J Casabona ${ }^{1,3,4}$, the Partner Notification Study Group ${ }^{15}$

1. Centre for Epidemiological Studies on Sexually Transmitted Infections and HIV/AIDS of Catalonia (CEEISCAT), Catalan

Institute of Oncology (ICO), Public Health Agency of Catalonia (ASPCAT), Barcelona, Spain

2. Pompeu Fabra University, Barcelona, Spain

3. Department of Paediatrics, Obstetrics, Gynaecology and Public Health of the Autonomous University of Barcelona, Bellaterra, Barcelona, Spain

4. Centros de Investigación Biomédica en Red Epidemiología y Salud Pública (CIBERESP), Spain

5. Sexually Transmitted Infections Unit, Drassanes Primary Health Centre, Catalan Institute of Health, Barcelona, Spain

6. Epidemiological Surveillance Unit, Lleida, Spain

7. Care Programme for sexual and reproductive health, Badalona Care Services, Barcelona, Spain

8. Care programme for sexual and reproductive health, Catalan Institute of Health, Barcelona, Spain

9. Care programme for sexual and reproductive health, Catalan Institute of Health, Sabadell, Spain

10. Salt Primary Health Centre, Catalan Institute of Health, Girona, Spain

11. Department of Andrology, Puigvert Foundation, Barcelona, Spain

12. Sexually Transmitted Infections Unit, Cerdanyola Primary Health Centre, Catalan Institute of Health, Barcelona, Spain

13. Care programme for sexual and reproductive health, Catalan Institute of Health, Esquerra de l'Eixample, Barcelona, Spain

14. Care programme for sexual and reproductive health, Catalan Institute of Health, Manresa, Barcelona, Spain

15. The members of the group are listed at the end of the article

Citation style for this article:

Tuneu MJ, Vallès X, Carnicer-Pont D, Barberá MJ, Godoy P, Avecilla-Palau A, Jordà B, Lopez-Grado E, Rivero D, Vives A, Acera A, Almirall R, Crespo N, Casabona J, the Partner Notification Study Group. Pilot study to introduce a notification card for partner notification of sexually transmitted infections in Catalonia, Spain, June 2010 to June 2011 . Euro Surveill. 2013;18(27):pii=20516. Available online: http://www.eurosurveillance.org/ViewArticle.aspx?Articleld=20516

Article submitted on 04 August 2012 / published on 04 July 2013

We conducted a cross-sectional study in 10 primary care centres in Catalonia, to determine applicability, acceptability and effectiveness of partner notification cards used by patients diagnosed of a sexually transmitted infection (STI) and to characterise these and their sexual partners. Statutorily notifiable STIs included Chlamydia infection, gonorrhoea, syphilis, human immunodeficiency virus (HIV) infection or other STIs as deemed necessary by the treating physician. Between June 2010 and June 2011, 219 index cases were enrolled, of whom 130 were men (59.4\%), 71 of them men who have sex with men (54.6\%). Chlamydia infection $(41.1 \%)$, gonorrhoea (17.8\%) and syphilis (16.0\%) were the STIs most frequently diagnosed. HIV infection accounted for $4 \%$ of cases. A total of 687 sexual partners were reported, and 300 of these were traceable through the notification card $(45.7 \%)$. Those who did not report traceable contacts were older (mean age: 34 years versus 31 years, $p=0.03$ ). The main reason for not distributing the card was anonymous sexual intercourse (38\%). Patient referral notification cards can reach a high percentage of sexual partners at risk. However, only few notified sexual partners attended participating health centres. Internet-based partner notification may be considered in order to reach those partners not otherwise traceable.

\section{Introduction}

Partner notification is the process through which sexual partners of a patient diagnosed with a sexually transmitted infection (STI) are informed that they have been exposed to infection, so they can be assessed, diagnosed and treated [1]. Partner notification is based on the assumption that the transmission chain of STI can be interrupted when both symptomatic and asymptomatic exposed individuals are assessed, diagnosed and treated appropriately [2]. Partner notification for STIs is specifically indicated in cases of Chlamydia infection, gonorrhoea, syphilis, or human immunodeficiency virus (HIV) infection [3,4]. Although there is no formal indication or enough evidence to recommend partner notification for other STIs, it may be reasonable in certain circumstances and at the discretion of the treating physician. Clinicians are asked to perform partner notification, but other health professionals such as nurses or social agents can also play a role. Patient referral partner notification seems to be the most cost-effective method compared with other partner notification strategies such as provider referral, conditional referral (where the provider informs the sexual partner(s) in case the patient fails to do so within an agreed period of time) or patient-delivered partner therapy. In a patient referral methodology, only the index case is responsible for notifying their sexual partners of possible infection. The effectiveness of this 
process can be increased with the use of a notification card $[5,6]$.

In recent years, Catalonia has experienced a re-emergence of syphilis and HIV infections, the emergence of Neisseria gonorrhoeae strains resistant to ceftriaxone $[7,8]$, and outbreaks of Lymphogranuloma venereum [9]. Catalonia has an adult population (15 to 64 years) of almost 5 million [10], and more than 600 new HIV cases were reported in the year 2011 (rate: 8.5/100,000 inhabitants) [11]. Moreover, increased mobility of people, the use of the Internet to find sexual partners (casual and anonymous), and the decreased use of barrier methods are all contributing to the spread of all STI [12-15]. In Spain, no formal guidelines for partner notification have been published yet, nor have there been studies evaluating partner notification. In contrast, 11 of the 24 European Union and European Economic Area (EU/EEA) countries that responded to the survey have regulated partner notification by law $[16,17]$, although only three (Finland, Norway and Sweden) currently observe compulsory partner notification by the health provider and the patient. In Catalonia there has been an increasing interest in implementing partner notification within primary care services since 2007, when gonorrhoea, syphilis, Lymphogranuloma venereum and HIV infection were included as statutorily notifiable infections. The latest version of the STI guidelines published by the Catalan Department of Health strongly recommends partner notification [18], but no standard guidelines or specific support for partner notification have been developed, although there are health centres that have designed their own notification card. For these reasons, a notification card was designed specifically for this study, in order to increase the coverage and efficiency of partner notification as well as to unify and standardise the available tools.

The goal of this study was to facilitate the introduction and standardisation of partner notification for STIs in primary care centres in Catalonia, including the specialist STI unit. We evaluated the applicability (ability of this tool or procedure to be used under real conditions in primary health centres and STI units), and acceptance of this method (willingness and satisfaction of the staff with the use of the tool or procedure to be used under real conditions in primary health centres and STI units), as well as its effectiveness in notifying as many sexual partners of the index case as possible with the support of a notification card. Secondly, we aimed to describe the profile of patients with STIs and their sexual partners.

\section{Methods}

\section{Study population}

Patients diagnosed with an STI (either clinically or by laboratory test) and attending, during the study period from June 2010 to June 2011, primary care centres (primary health physicians, gynaecologists and midwives) or the Sexually Transmitted Infection specialist unit (STI unit) were eligible to be enrolled in the study.

\section{Study design}

A cross-sectional study was carried out. The study was set up in 10 primary care centres in Catalonia. These centres represented different models of primary STI care (public STI reference units, public and private primary care) and were located in either rural or urban areas. Patients were continuously enrolled during the study period (June 2010 to June 2011). All health professionals participating in the study shared the same standard approaches to STI, defined in the current guidelines for the control and management of STIs in Catalonia [14]. Biological samples were collected from symptomatic patients from the anatomical site of suspicious symptoms, and followed the same laboratory procedures. No further standard criteria were established for additional collection of samples or the screening of asymptomatic partners, e.g. rectal or pharyngeal swabs, these being taken entirely at the discretion of the treating clinician.

Once a laboratory-confirmed STI or suspected (syndromic) case was diagnosed, the index case filled in a specific epidemiological questionnaire. Data collected included: date of index case presenting to the health centre, age, sex, sexual orientation, number of sexual partners during the theoretical infectious period according to clinical guidelines [18], type of relationship (casual or stable), number of partners eligible for being contacted independently of the tool (paper card, SMS, telephone, internet, etc) and of these, the number of partners suitable for notification using the notification card, and reasons why the notification card was not used. Eligible partners were all those that, for each specific infection, had a sexual relationship with the index case within the period of infectiousness, defined by days or months backwards from the date of onset of symptoms in the index case. Eligible partners were classified as: eligible for partner notification using the paper card and those eligible for partner notification using other methods than the card. Partners testing positive were also enrolled as new index cases.

A number of cards equal to the number of partners eligible for being contacted by notification card were distributed to each index case. The health professional received personally the notification card from the notified partner, holding information of date of diagnosis of infection, type of infection, syndromic or laboratory-confirmed, and treatment given to the index case. Syndromic diagnoses were specifically written in a blank space in the notification card: (e.g. urethral syndrome). By counting the notification cards received from notified partners at health centres and recording the date of the partner presenting at the health centre we evaluated the effectiveness of using this notification card. 


\section{FIGURE 1}

Type of relationship of index cases by sex and sexual orientation, partner notification study, Catalonia, June 2010 to June $2011(\mathrm{n}=219)$

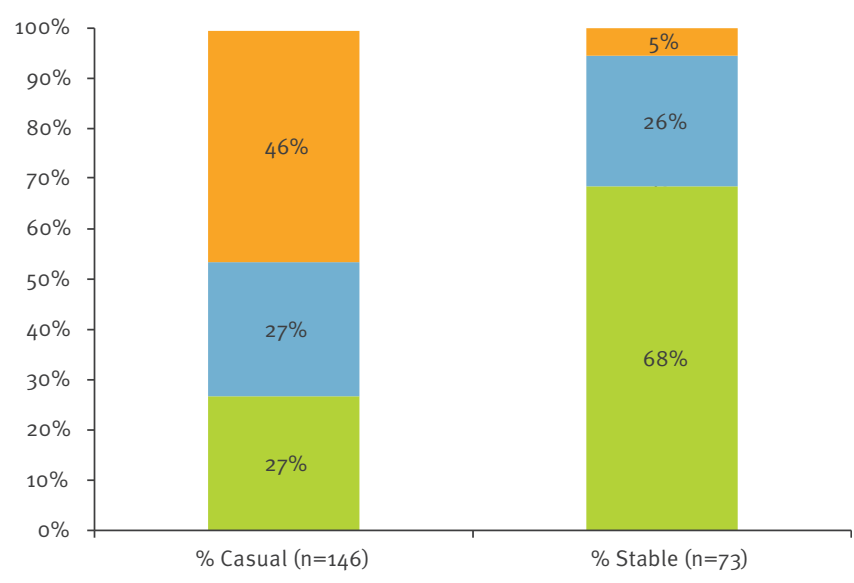

MSM Men HTS Women HTS

HIV: human immunodeficiency virus; HTS: heterosexual; MSM: men who have sex with men.

Index cases stating that it would not be possible for them to trace any of their eligible partners for notification were qualified as non-notifier index cases.

Laboratory results from the index case were included once they were available (including negative results without any alternative diagnosis). For STIs such as HIV infection and syphilis, partner notification did not start until laboratory results were available. A presumptive clinical diagnosis of Lymphogranuloma venereum in men who have sex with men (MSM) triggered a request to subtype Chlamydia trachomatis. For other STIs such as Trichomonas or herpes simplex infections, causing urethral syndrome or genital herpes, syndromic diagnosis was considered sufficient to start partner notification procedures.

The notification card and the epidemiological questionnaire were piloted by two health professionals with some of their patients for a week prior to their use during the study. This allowed us to adapt both the notification card and the questionnaire, so as to include more understandable words and sentences. Data from patients interviewed during the pilot study were not included in the study.

\section{Data management and analysis}

Data collected from the index case's epidemiological questionnaire, from the notification cards and from the questionnaire on acceptability completed by health professionals, were validated and entered into a database designed specifically for the study. Data analysis was done using STATA 10.0 (Statacorp, Texas, United States). Mean, range, 95\% confidence interval (CI) and standard deviation (SD) were calculated for quantitative variables. Proportions and $95 \% \mathrm{Cl}$ for binomial distributions were calculated for qualitative variables. Chi-square and Fisher's exact test were used for bivariate analysis of qualitative variables and Student's T-test for quantitative variables. Men were stratified into two groups: i) MSM, including bisexuals, and ii) heterosexual men. All women were included in a single category. Casual sexual intercourse was defined as an occasional relationship with a partner not considered stable. Relationships lasting more than three months were considered stable. Index cases with negative laboratory results were not excluded from the analysis, having established that there were no socio-demographic differences between index cases with negative and those with positive results. Primary, early latent and secondary syphilis were included in the same category.

\section{Ethical issues}

Partner notification is indicated once there is a diagnosis of a statutorily notifiable STI [17]. Informed consent form was therefore not obtained by the health professional. This study was approved by the Ethics Committee of the Hospital Universitari Germans Trias i Pujol. Data in the coordinating centre (Centre for Epidemiological Studies on Sexually Transmitted Infections and HIV/AIDS of Catalonia; CEEISCAT) were treated strictly confidentially following standard procedures. Health professionals participating in the study used their daily practice to contribute to this study.

\section{Results}

General description of index cases and distribution of sexually transmitted infections During the study period, 219 index cases were included (mean age: 32.2 years, SD: 9.3 years, range: 15-57 years), 97 (44\%) of whom were recruited in the STI Unit. They were 130 (59\%) men and 89 (41\%) women. Among men, 71 (55\%) were MSM. Most of the MSM were seen at the STI unit $(n=63,89 \%)$. MSM were older than heterosexual cases (men and women) (34.8 versus 30.9 years, $p=0.001)$.

Casual relationships were more frequently mentioned by index cases $(67 \%)$ than stable relationships $(33 \%)$ (Table 1). Fifty (68\%) of the 73 index cases reporting stable relationships were heterosexual women. In contrast, the most frequent sexual orientation among the 146 index cases reporting casual relationships were MSM (46\%) (Figure 1). We registered 213 laboratoryconfirmed STIs from 239 STI diagnoses (syndromic and laboratory-confirmed), including 20 cases with multiple infections (19 subjects with two infections and one with three infections). A detailed description of the index cases is shown in Table 1 . The total number of statutorily notifiable STIs (Chlamydia infection, gonorrhoea and syphilis, excluding HIV infection) included in 
TABLE 1

Characteristics of the index cases, partner notification study, Catalonia, June 2010 to June 2011 (n=219)

\begin{tabular}{|c|c|c|c|}
\hline Variable & Number of cases & Percentage of index cases & $95 \% \mathrm{Cl}$ \\
\hline \multicolumn{4}{|l|}{ Age $(n=219)$} \\
\hline $15-25$ & 53 & 24 & $18.7-30.1$ \\
\hline $26-35$ & 98 & 45 & $38.0-51.6$ \\
\hline $36-45$ & 44 & 20 & $15.0-26.0$ \\
\hline$>45$ & 24 & 11 & $7.1-15.9$ \\
\hline \multicolumn{4}{|l|}{$\operatorname{Sex}(n=219)$} \\
\hline Men & 130 & 59 & $52.5-65.9$ \\
\hline Women & 89 & 41 & $34.0-47.5$ \\
\hline \multicolumn{4}{|l|}{ Sexual orientation $(n=219)$} \\
\hline Heterosexual women & 89 & 41 & $34.0-47.5$ \\
\hline Heterosexual men & 59 & 27 & $21.2-33.3$ \\
\hline MSM & 71 & 32 & $26.3-39.1$ \\
\hline \multicolumn{4}{|l|}{ Relationship $(n=219)$} \\
\hline Casual & 146 & 67 & $60.0-72.9$ \\
\hline Stable & 73 & 33 & $27.1-40.0$ \\
\hline \multicolumn{4}{|c|}{ Laboratory and syndromic diagnosis $\left(n=239\right.$ diagnoses) ${ }^{a}$} \\
\hline Chlamydia infection & 90 & $42^{b}$ & $31.4-44.1$ \\
\hline Lymphogranuloma venereum & 2 & $2^{c}$ & $0.3-7.8$ \\
\hline Gonorrhoea & 39 & $18^{\mathrm{b}}$ & $11.9-21.6$ \\
\hline HIV infection & 9 & $4^{\mathrm{b}}$ & $1.7-7.0$ \\
\hline Syphilis & 35 & $16^{\mathrm{b}}$ & $10.4-19.8$ \\
\hline Primary syphilis & 14 & $40^{c}$ & $23.9-57.9$ \\
\hline Secondary syphilis & 10 & $29^{c}$ & $14.6-46.3$ \\
\hline Early latent syphilis & 4 & $11^{c}$ & $3.2-26.7$ \\
\hline Latent syphilis & 7 & $20^{c}$ & $8.4-36.9$ \\
\hline Other laboratory-positive and syndromic STI ${ }^{\mathrm{d}}$ & 40 & $19^{\mathrm{b}}$ & $12.2-22.1$ \\
\hline Laboratory-positive and syndromic STI & 213 & $89^{\mathrm{e}}$ & $84.4-92.7$ \\
\hline Laboratory-negative & 26 & $11^{\mathrm{e}}$ & $7.2-15.5$ \\
\hline \multicolumn{4}{|c|}{ Number of sexual partners mentioned by index case $(\mathrm{n}=687$ partners) } \\
\hline $0-1$ & 103 & 47 & $40.3-53.9$ \\
\hline $2-3$ & 65 & 30 & $23.7-36.2$ \\
\hline 33 & 51 & 23 & $17.9-29.5$ \\
\hline \multicolumn{4}{|c|}{ Notification card distributed by index case ( $n=300$ cards) } \\
\hline o & 48 & 22 & $16.6-28.0$ \\
\hline $1-3$ & 161 & 73 & $67.1-79.2$ \\
\hline 13 & 10 & 5 & $2.2-8.2$ \\
\hline \multicolumn{4}{|c|}{ Reason for not using the notification card $\left(n=99\right.$ index cases) ${ }^{f}$} \\
\hline Anonymous sexual partner & 43 & 38 & $27.5-45.4$ \\
\hline Sexual partner lives far & 34 & 30 & $21.8-39.4$ \\
\hline It is not necessary to notify & 8 & 7 & $3.1-13.5$ \\
\hline Other & 28 & 25 & $17.1-33.8$ \\
\hline
\end{tabular}

$\mathrm{Cl}$ : confiidence interval; HIV: human immunodeficiency virus; MSM: men having sex with men; STI: sexually transmitted infection.

a Includes 19 patients with two infections (Neisseria gonorrheae+Chlamydia trachomatis, $\mathrm{n}=7$; C. trachomatis + Trichomonas vaginalis, $\mathrm{n}=2$; C. trachomatis+Ureaplasma urealyticum, $\mathrm{n}=1 ;$ C. trachomatis+Treponema pallidum, $\mathrm{n}=2 ;$. N. gonorrhoeae+T. pallidum, $\mathrm{n}=1$;

HIV $+C$. trachomatis, $n=1 ; H I V+T$. pallidum, $n=2 ; H I V+T$. vaginalis, $n=2 ; U$. urealyticum + Mycoplasma genitalium, $n=1$ ) and one patient with three infections (C. trachomatis+N. gonorrhoeae+U. urealyticum).

b Percentage of the type of infection over all laboratory-positive and syndromic STI $(n=213)$.

Percentage of cases within each category.

d T. vaginalis $(n=20)$, Human papillomavirus $(n=6)$, Hepatitis B virus $(n=4), U$. urealyticum $(n=4)$, M. genitalium $(n=3)$, Herpes simplex $(n=3)$.

e Percentage of results over all laboratory and syndromic diagnoses $(n=239)$.

$f$ This question accepted more than one answer. 
Distribution of sexually transmitted infections by sex and sexual orientation, partner notification study, Catalonia, June 2010 to June $2011(n=219)^{a}$

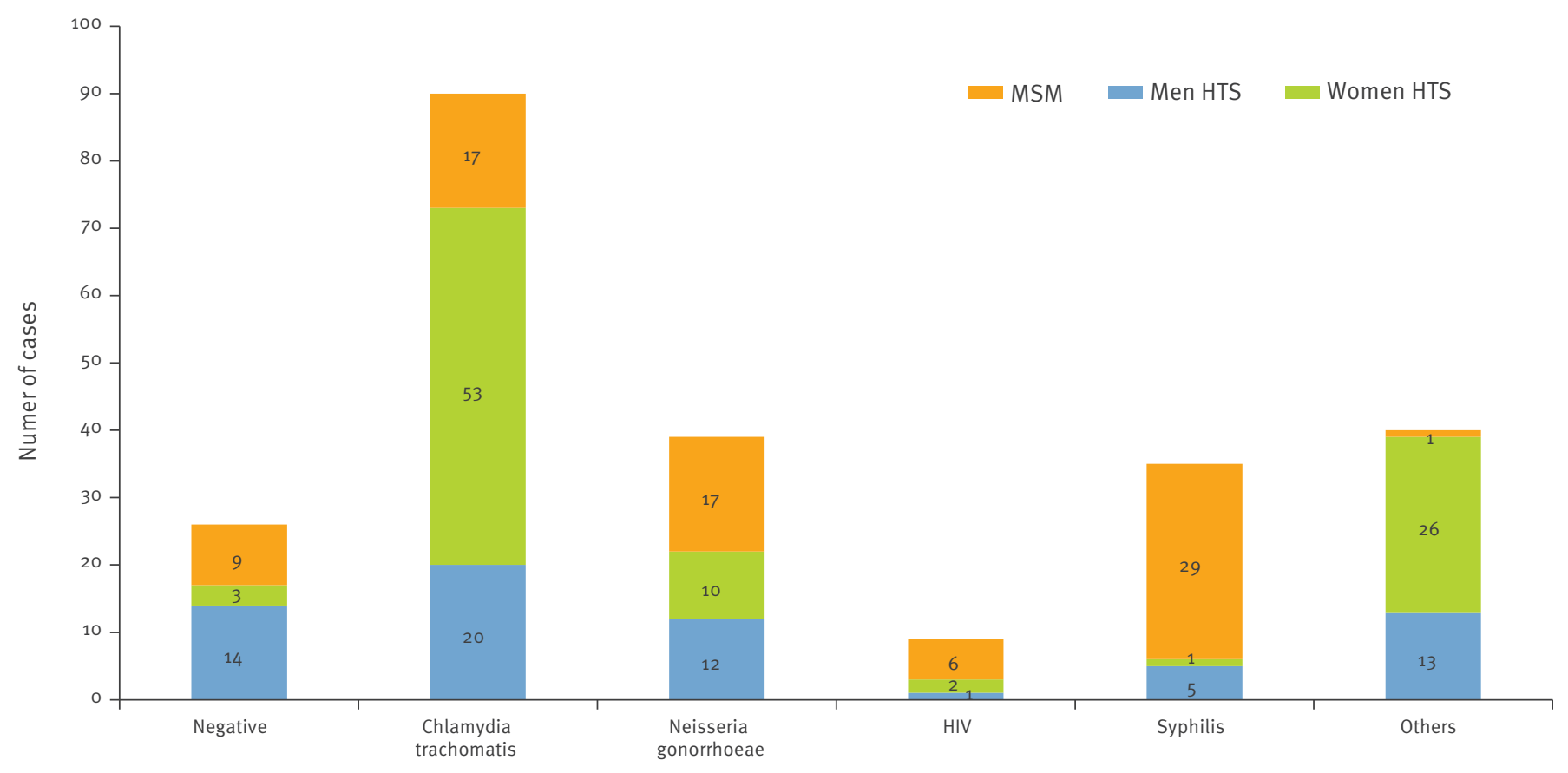

HIV: human immunodeficiency virus; HTS: heterosexual; MSM: men who have sex with men.

a The 219 cases had a total of 239 diagnoses and included 19 patients with two infections (Neisseria gonorrheae+Chlamydia trachomatis, $\mathrm{n}=7$; C. trachomatis+Trichomonas vaginalis, $\mathrm{n}=2$; C. trachomatis + Ureaplasma urealyticum, $\mathrm{n}=1 ; \mathrm{C}$. trachomatis + Treponema pallidum, $\mathrm{n}=2$; N. gonorrhoeae+Treponema pallidum, $\mathrm{n}=1 ; \mathrm{HIV}+\mathrm{C}$. trachomatis, $\mathrm{n}=1 ; \mathrm{HIV}+$ Treponema pallidum, $\mathrm{n}=2 ; \mathrm{HIV}+T$. vaginalis, $\mathrm{n}=2$;

$U$. urealyticum + Mycoplasma genitalium, $\mathrm{n}=1$ ) and one patient with three infections (C. trachomatis $+N$. gonorrhoeae+U. urealyticum).

the study was 164 representing $15 \%$ of all STIs declared in Catalonia during the study period $(n=1,158)$.

The most frequent STIs were: Chlamydia infection, including two cases of Lymphogranuloma venereum, $(41 \%, n=90)$, gonorrhoea $(18 \%, n=39)$ and syphilis $(16 \%, n=35)$. HIV infection accounted for $4 \% \quad(n=9)$ and all were newly diagnosed HIV infections. Other STIs represented $18 \%(n=40)$ of the sample. Twentysix patients had negative laboratory results and their diagnosis was therefore exclusively clinical and syndromic (12\%).

Figure 2 shows the number of STIs by diagnosis, sex and sexual orientation. The proportion of women among Chlamydia-infected patients was higher than that of heterosexual men (53 of 90 versus 20 of 90 , $p=0.002$ ). Syphilis was proportionally more frequent among MSM than heterosexual men (29 of 35 versus 5 of 35 p 0.001$)$. Most HIV infections were in MSM compared with the heterosexual population (6 of 9 versus 3 of $9, p=0.03)$. Both cases of Lymphogranuloma venereum were diagnosed in MSM.
Number of sexual partners and cards distributed and recovered Overall, the index cases reported having had 687 sexual partners during the infectious period (range: 1-30, mean: 3 partners per index case). Female index cases reported a mean of 1.7 sexual partners, heterosexual men of 1.7, and MSM of 6.2 (p<0.001).

A total of 300 notification cards were reported to be distributed by the index cases to their sexual partners (corresponding to 300 sexual contacts eligible to be contacted using the notification card). The remaining 387 partners were those eligible to be notified by other means than partner notification paper card, including those that may be impossible to trace by the index case. There were 59 notification cards distributed to heterosexual men, who reported a total of 100 sexual partners (ratio of cards distributed/contacts reported: 0.59, 95\% Cl: 0.48-0.68). There were 108 notification cards distributed to women who reported a total of 144 sexual partners (ratio: $0.75,95 \% \mathrm{Cl}: 0.62-0.79$ ) and 133 to MSM who reported 443 sexual partners (ratio: $0.30,95 \% \mathrm{Cl}: 0.26-0.35)$. 
Characteristics of non-notifier ${ }^{\text {a }}$ group of index cases, partner notification study, Catalonia, June 2010 to June $2011(n=48)$

\begin{tabular}{|c|c|c|c|}
\hline Variable & Number & Percentage ${ }^{b}$ & $p$ value ${ }^{c}$ \\
\hline \multicolumn{4}{|c|}{ Sexual orientation $(n=48)$} \\
\hline Heterosexual women & 10 & 11 & \multirow{3}{*}{$0.003^{d}$} \\
\hline Heterosexual men & 20 & 34 & \\
\hline MSM & 18 & 25 & \\
\hline \multicolumn{4}{|l|}{ Relationship $(n=48)$} \\
\hline Casual & 37 & 25 & \multirow{2}{*}{$0.08^{d}$} \\
\hline Stable & 11 & 15 & \\
\hline \multicolumn{4}{|l|}{ Age $(n=48)$} \\
\hline $15-25$ & 7 & 13 & \multirow{4}{*}{$0.17^{d}$} \\
\hline $26-35$ & 21 & 21 & \\
\hline $36-45$ & 12 & 27 & \\
\hline$>45$ & 8 & 33 & \\
\hline \multicolumn{4}{|c|}{ Number of sexual partners referred $(n=48)$} \\
\hline $0-1$ & 29 & 28 & \multirow{3}{*}{$0.08^{d}$} \\
\hline $2-3$ & 9 & 14 & \\
\hline$>3$ & 10 & 20 & \\
\hline \multicolumn{4}{|c|}{ Laboratory diagnosis $(n=55)^{e}$} \\
\hline Chlamydia infection & 16 & 18 & 0.2 \\
\hline Gonorrhoea & 9 & 23 & 0.8 \\
\hline HIV & 3 & 33 & 0.4 \\
\hline Syphilis & 9 & 26 & 0.6 \\
\hline Other STI & 8 & 20 & 0.8 \\
\hline Negative & 10 & 38 & 0.03 \\
\hline
\end{tabular}

HIV: human immunodeficiency virus; MSM: men having sex with men; STI: sexually transmitted infection.

a Non-notifier index cases are those stating that it would not be possible for them to trace any of their eligible partners for notification either using a notification paper card or by other means.

b The denominator was the total of individuals included in the respective groups as presented in Table 1 (e.g. 10 non-notifie HTS women among 89 HTS persons included in the study). The baselines are considered as the group of notifiers.

d $P$ test for trend.

e The number of laboratory results $(n=55)$ exceeds the number of non-notifier index cases because some of them had more than one STI.

The ratio of cards distributed/contacts reported was lowest among MSM, followed by heterosexual men and heterosexual women ( $p$ test for trend $=0.003$ ). Overall, thirty-one cards were returned to participating health centres (10\%) and the card holders were assessed by health professionals and treated as necessary following diagnosis. This percentage was higher in the STI Unit $(20 \%, p=0.003)$. The main reason for not using a notification card was that sexual contact was anonymous $38 \%$. Those partners that were notified by index cases but did not deliver a notification card or mention it on arrival at the health centre were not registered as contacts and were only enrolled as index cases.

\section{Non-notifier index cases}

Of the 219 index cases enrolled in the study, 99 (45\%) stated that it would be impossible to use the notification card at least for one of their partners. Among them were 48 (48\%) for whom it was impossible to notify any of their partners (non-notifiers). These nonnotifier index cases were older than other index cases (34 versus 31 years, $p=0.03$ ), independently of sexual orientation. In Table 2 we show a detailed description of non-notifier index cases.

\section{Discussion}

This is the first study evaluating partner notification for STIs in Catalonia or Spain. Most of our findings are in line with recently published studies in the United States (US) and Switzerland $[19,20]$, which reported higher-risk behaviour by MSM (greater number of sexual partners, including casual and anonymous sexual intercourse), and a higher proportion of syphilis among MSM and Chlamydia infection among women.

It is of note that female index cases indicated that they were able to give the card to their sexual partners more often than heterosexual men (ratio 0.75 versus 0.59 ). This can be explained by socio-cultural perceptions, or more probably, by the type of relation maintained with sexual partners (more frequently stable). We suspect that women were more frequently infected by their stable partner than other groups.

One finding of our study is the relatively low yield of partner notification cards distributed and recovered (patients returned). However, we consider this number as an underestimation. This study was not designed for collecting returned cards, although a certain number were collected by the participating centres. Given that there are hundreds of primary care and private centres in Catalonia that can see individuals with suspected STIs, the study was unable to include all these centres, and could thus only focus on a limited and representative number of centres. Moreover, a certain number of contacts may have visited a health centre without presenting the card (uncontrolled).

We also suspect that a lack of awareness and lack of concern about asymptomatic sexually transmitted infections may be one of the explanations for the low proportion of sexual partners presenting to health centres after being notified by the index case.

It is important to mention that a larger proportion of cards were retrieved in the STI unit compared with the rest of the participating centres (not specialised, 20\%). This relatively high percentage may be attributable to the specialised attention given to patients in the STI 
unit and the higher probability of effectively assessing and treating sexual partners of index case seen in this unit.

The main finding of our study with respect to partner traceability is that close to half of all sexual partners were traceable through a notification card distributed by the index cases $(n=300$ of $687,44 \%)$ but it is also important to note the high number of partners that could not be contacted due to anonymous and casual sexual intercourse.

Consequently, additional notification strategies should be implemented to reach a higher proportion of exposed contacts and to overcome communication barriers. One of the strategies is email or website notification using pseudonyms. The use of the internet is becoming highly popular for sexual partner research, especially among high-risk groups. The use of email and specially designed websites under the control of health authorities can guarantee confidentiality and quality of the information given to sexual partners exposed. In fact, this may be the only way to contact a majority of sexual partners [21-24]. Some clinics in the US and Australia are already using this technology with promising results $[25,26]$. However, most of the literature about partner notification for STI was carried out in other countries with different socio-cultural contexts such as Australia, Canada, the US, Guatemala and Kenya. We cannot ascertain the real impact of this strategy (number of sexual partners finally screened in health services), and we relied on the previous studies that evaluated these indicators $[2,6,27,28]$

Since this study was done under real conditions in each health centre, a standard protocol to test sexual partners was not used in our study. Therefore, the testing of sexual partners may have been addressed differently by the participating centres. Comprehensive routine or sexual practice-based screening of different anatomical sites (rectal and pharyngeal swabs in the case of anal or oral intercourse) was not standard procedure. Although sexual partners attending health centres with a notification card were assessed according to their sexual orientation, sexual practice and symptoms, we cannot ensure that comprehensive testing was done by all participating centres in all sexual partners, independently of the presence of symptoms. In Catalonia, despite current guidelines recommending partner notification, there is still no clear partner notification strategy, a gap which needs to be closed. Considering the high proportion of asymptomatic STIs, comprehensive screening of sexual partners, irrespective of the presence of symptoms, should be offered by all health professionals treating STIs, in order to optimise partner notification practices and improve their effectiveness.

In conclusion, partner notification through the use of a notification card is a feasible (applicable and acceptable) strategy in Catalonia given its high acceptability among healthcare workers and index cases. Nevertheless, there are some variations in the use of the notification paper card, MSM being the ones with more difficulties to use it due to the highest number of anonymous sexual contacts. Moreover, the capacity of the card to bring contacts to the healthcare system is very sensitive to the awareness of health professionals and the site where they are working (STI unit, Care Programme for Sexual and Reproductive Health or primary healthcare physician), and also depends on whether the population knows about the services provided by each centre. Therefore, there is room for improvement in the healthcare system derivation procedures.

In addition, further strategies should be developed and implemented to maximise the impact of partner notification strategies, such as web-based notification for anonymous contacts using pseudonymous name. Finally, there is a need for a clear partner notification strategy including guidelines on testing procedures according to sexual orientation and sexual practice, and independently of the presence of symptoms.

\section{Acknowledgements}

We wish to acknowledge Dr. Colin Campbell for a review of English and the healthcare professionals participating in the study.

Members of the Partner Notification Study Group

Anna Sabaté, Manel Baradad, Marcel•li Huguet, Maria Josep Garrofé, Irma Mòdol (Epidemiological Surveillance Unit, Lleida), Edit López-Grado, Montserrat Villanueva, Josep Sobrino Sarinas, Montserrat Abella Jové, Ramon Espelt i Badia, Gemma Falguera (Care programme for sexual and reproductive health, Sabadell), Mercedes Teixidó, Diana Mateo (Care Programme for sexual and reproductive health, ASSIR Badalona), M del Carmen Bergós, Montserrat Galí Garcia, Pilar Piqué (Care programme for sexual and reproductive health ASSIR, Manresa, Barcelona), Imma Castellà, Laura Sala, Victoria Sala, Maria Lluïsa Parejo, Clara Michaut, Araceli Gonzalez, Montser Pujiula, Laura Taberner (Salt Primary Health Centre, Girona), Maider Arando, Martí Vall, Pere Armengol (Sexually Transmitted Infections Unit. Drassanes Primary Health Centre. Catalan Health Institute) Neus Camps, Maria Company (Regional Epidemiological Surveillance Unit, Girona), M Rosa Sala (Regional Epidemiological Surveillance Unit of BarcelonaVallés), Roser Torra (Regional Epidemiological Surveillance Unit of Central Catalonia), Patricia Garcia de Olalla, Joan Caylà (Epidemiological surveillance unit of the Public Health Agency of Barcelona) 


\section{References}

1. Cowan FM, French R, Johnson AM. The role and effectiveness of partner notification in STD control: a review. Genitourin Med 1996;72(4):247-52. PMCid:PMC1195671.

2. Vallès X, Carnicer-Pont D, Casabona J. Estudio de contactos para infecciones de transmisión sexual. ¿Una actividad descuidada? [Partner notification in sexually transmitted infections. A neglected activity?]. Gac Sanit. 2011;25(3):224-32. Spanish.

3. Partner notification of sexually transmitted infections in New South Wales: An informed literature review. Melbourne: Burnet Institute; June 2010. Available from: http://www.stipu.nsw.gov. au/content/Document/NSW_STI_PN_PDF.pdf

4. Holmes KK, Mardh PA, Sparling PF, editors. Sexually transmitted diseases. 2nd ed. New York: Mc Graw-Hill; 1990; pp 996.

5. Wakasiaka SN, Bwayo Jl, Weston K, Mbithi J, Ogol C. Partner notification in the management of sexually transmitted infections in Nairobi, Kenya. East Afr Med J. 2003;80(12): 64651. PMid:15018422.

6. Ellis S, Grey A. Prevention of sexually transmitted infections (STIs): a review of reviews into the effectiveness of non-clinical interventions. London: Health Development Agency (HDA); 2004. Available from: http://www.nice.org.uk/nicemedia/ documents/prevention_stis_evidence_briefing.pdf

7. Carnicer-Pont D, Smithson A, Fina-Homar E, Bastida MT and the Gonococcus antimicrobial resistance surveillance working group. First cases of Neisseria gonorrhoeae resistant to ceftriaxone in Catalonia. Spain. May 2011. Enferm Infecc Microbiol Clin. 2012;30(4):218-9. http://dx.doi.org/10.1016/j. eimc.2011.11.010

8. Cámara J, Serra J, Ayats J, Bastida T, Carnicer-Pont D, Andreu A, et al. Molecular characterization of two high-level ceftriaxoneresistant Neisseria gonorrhoeae isolates detected in Catalonia, Spain. J Antimicrob Chemother. 2012;67(8):1858-60. http:// dx.doi.org/10.1093/jac/dks162. PMid:22566592

9. Centre d'Estudis Epidemiològics sobre les Infeccions de Transmissió Sexual i Sida de Catalunya (CEEISCAT). [Centre of excellence on HIV and Sexually Transmitted Infections (STI) epidemiology in Catalonia. (CEEISCAT)]. Sistema Integrat de vigilància epidemiològica de la SIDA/VIH/ITS a Catalunya (SIVES). [Integrated epidemiological surveillance of AIDS/HIV STI in Catalonia (SIVES)]. Technical document 19. Barcelona: Generalitat of Catalonia, Department of Health; 2008. Spanish. Available from: http://www20.gencat.cat/docs/canalsalut/ Minisite/ObservatoriSalut/ossc Dades estadistiques/ Estat_salut_estils_vida/Temes_especifics_salut/Malalties_ infeccioses/VIH/FItxers_estatics/Informe_biennal_ sives_2008.pdf

10. Population. By sex and age groups. Year 2011. Barcelona: Statistical Institute of Catalonia (IDESCAT). [Accessed: Dec 2011]. Spanish. Available from: http://www.idescat.cat/ $\mathrm{pub} / \mathrm{?}$ id $=\mathrm{aec} \& \mathrm{n}=\mathbf{2 5 3}$ \&lang $=\mathrm{en}$

11. Indicadors de vigilància. [Surveillance indicators.] Centre d'Estudis Epidemiològics sobre les Infeccions de Transmissió Sexual i Sida de Catalunya (CEEISCAT). [Centre of excellence on HIV and Sexually Transmitted Infections (STI) epidemiology in Catalonia (CEEISCAT)]. Sistema Integrat de vigilància epidemiològica de la SIDA/VIH/ITS a Catalunya (SIVES). [Integrated epidemiological surveillance of AIDS/HIV/STI in Catalonia (SIVES)]. Technical document 21. Spanish. Barcelona: Generalitat of Catalonia, Department of Health; 2012. Available from: http://www2o.gencat.cat/docs/canalsalut/Minisite/ ObservatoriSalut/ossc_Dades_estadistiques/Estat_salut_ estils vida/Temes especifics salut/Malalties infeccioses/ VIH/Fitxers_estatics/Informe_biennal_sives_2012.pdf

12. Vest JR, Valadez AM, Hanner A, Lee JH, Harris PB. Using e-mail to notify pseudonymous e-mail sexual partners. Sex Transm Dis. 2007;34(11):840-5. http://dx.doi.org/10.1097/ OLQ.obo13e318073bd5d

13. Likatavicius G, van de Laar MJ. HIV infection and AIDS in the European Union and European Economic Area, 2010. Euro Surveill. 2011;16(48):pii=20030. Available online: http://www. eurosurveillance.org/ViewArticle.aspx?Articleld=20030

14. Folch C, Casabona J, Mu-oz R, Gonzalez V, Zaragoza K. Increase in the prevalence of HIV and in associated risk behaviours in men who have sex with men: 12 years of behavioural surveillance surveys in Catalonia.(Spain) Gac Sanit. 2010;24(1):40-6. Spanish. http://dx.doi.org/10.1016/j. gaceta.2009.06.010. PMid:19962792

15. Fernández-Dávila P, Zaragoza K. Internet y riesgo sexual en hombres que tienen sexo con hombres. [Internet and sexual risk in men who have sex with men.] Gac Sanit. 2009;23(5):380-7. Spanish. http://dx.doi.org/10.1016/j. gaceta.2008.11.004. PMid:19327870
16. Arthur G, Lowndes CM, Blackham J, Fenton KA; European Surveillance of sexually transmitted Infections (ESSTI) Network. Divergent approaches to partner notification for sexually transmitted infections across the European Union. Sex Transm Dis. 2005;32(12):734-41. http://dx.doi.org/10.1097/01. olq.0000175376.62297.73

17. European Centre for Disease Prevention and Control.(ECDC). Public health benefits of partner notification for sexually transmitted infections and HIV. Stockholm: ECDC; 2013. Available from: http://www.ecdc.europa.eu/en/publications/ Publications/Partner-notification-for-HIV-STI-June-2013.pdf

18. Guia de pràctica clínica sobre infeccions de transmission sexual. [Sexually Transmitted Diseases Clinical Guidelines]. GPC-ITS 2009. Barcelona: Generalitat of Catalonia, Department of Health; 2009 Spanish. Available from: http://www2o. gencat.cat/docs/canalsalut/Home\%20Canal\%20Salut/ Professionals/Temes de salut/Infeccions de transmissio sexual /documents/Acc\%C3\%A9s\%20a\%2ola\%20Guia.pdf

19. Schwartz RM, Malka ES, Augenbraun M, Rubin S, Hogben $M$, Liddon N, et al. Predictors of partner notification for C. trachomatis and N. gonorrhoeae: an examination of social cognitive and psychological factors. J Urban Health. 2006;83(6):1095-104. http://dx.doi.org/10.1007/ S11524-006-9087-9

20. Trelle S, Shang A, Nartey L, Cassell JA, Low N. Improved effectiveness of partner notification for patients with sexually transmitted infections: systematic review. BMJ.2007;334(7589):354. http://dx.doi.org/10.1136/ bmj.39079.460741.7C. PMid:17237298

21. Mimiaga MJ, Fair AD, Tetu AM, Novak DS, Vanderwarker R, Bertrand T, et al. Acceptability of an internet-based partner notification system for sexually transmitted infection exposure among men who have sex with men. Am J Public Health. 2008;98(6):1009-11. http://dx.doi.org/10.2105/ AJPH.2006.098467. PMid:17901442

22. Mimiaga MJ, Tetu AM, Gortmaker S, Koenen KC, Fair AD, Novak DS, et al. HIV and STD status among MSM and attitudes about Internet partner notification for STD exposure. Sex Transm Dis. 2008;35(2):111-6. http://dx.doi.org/10.1097/ OLQ.ob013e3181573d84. PMid:18007274

23. Tomnay JE, Pitts MK, Kuo TC, Fairley CK. Does the Internet assist clients to carry out contact tracing? A randomized controlled trial using web-based information. Int J STD AIDS. 2006;17(6):391-4. http://dx.doi. org/10.1258/095646206777323391. PMid:16734961

24. Fernández-Dávila P, Zaragoza-Lorca K. Trust and sexual interaction: The significance of the Internet on the sex life and sexual risk behaviours of gay and bisexual men in Spain. Int J of Sex Health. 2011;23(2):120-38. http://dx.doi.org/10.1080/19 317611.2011.566307

25. Gold J, Pedrana AE, Sacks-Davis R, Hellard ME, Chang S, Howard S, et al. A systematic examination of the use of Online social networking sites for sexual health promotion. BMC Public Health. 2011;11:583. http://dx.doi.org/10.1186/14712458-11-583 PMid:21777470

26. Levine D, Woodruff AJ, Rain-Mocello A, Lebrija J, Klausner JD. inSPOT: The First Online STD Partner Notification System Using Electronic Postcards. PLoS Med. 2008;5(10):e213. http:// dx.doi.org/10.1371/journal.pmed.0050213 PMid:18942887

27. Mathews C, Coetzee N. Partner notification. Clini Evid. 2009; $\mathrm{pii}=1605$.

28. Hogben M. Partner Notification for Sexually Transmitted Diseases. Clin Infect Dis. 2007:44(Suppl 3): S160-74. http:// dx.doi.org/10.1086/511429. PMid:17342669 